\title{
Present Situation and Countermeasures on Working Pressure of New Head Teacher in Primary School
}

\author{
Yuqi Zhang ${ }^{\mathrm{a}}$, Jun Yang ${ }^{\mathrm{b}}$ \\ School of Education and Sports, Bohai University, Jinzhou, 121013, China \\ a1048253330@qq.com, b444530141@qq.com
}

Keywords: primary school; new head teacher; working pressure; questionnaire investigation; present situation; countermeasures

\begin{abstract}
Pressure on everyone is there, the effects of different pressure are not the same. Pressure to a certain extent affects people's physical and mental health. In general, the people in the workplace stress are generally bigger. With the development of the society, everyone has different degree of feeling the pressure from different aspects. Teachers is a special profession, there are many unstable factors is facing some special groups. As a teacher in charge of the teachers, it is more stressful. Each shape of the teacher in charge start from "new", for the new teacher in charge, they don't have a clue about work, large workload, class, etc., it should not be very easy to generate a lot of pressure. According to the authority scale among a number of teachers in primary schools, analysis the new teacher in charge's work stress situation and find a reasonable solution.
\end{abstract}

\section{Introduction}

With the continuous development of society, education career gradually taken seriously by all people, teachers' work pressure is growing. Job stress has been defined like this: "teachers work stress is an individual to deal with those who think it is difficult to cope with is related to its education, teaching activities and life state, produced by the psychological and physical tension." [1], the new teacher in charge as a special group of the teachers, most of them are very solid professional knowledge and positive work enthusiasm. When their role transformation, need to face the students, colleagues, students, parents, society, all sorts of problems, such as the pressure will be relatively large. In this article, through the form of questionnaire, the analysis of several teachers' work pressure is presently as follows investigation process, result and analysis report.

\section{Questionnaire Investigation}

The teacher in charge of the work itself is more than other teachers and the most important thing is the teacher in charge to manage the whole class. In classes and grades daily management, there will be a lot of things. So for those of the new class, is undoubtedly a great challenge. In the long run, there will be a lot of pressure. At this point, there is the pressure of work [2-3].

In view of the elementary school, the new teacher in charge work pressure, design the questionnaire. Research a number of the new teacher in charge. According to the results of the survey respondents it will settle in a timely. The questionnaire is as follows:

Dear teacher:

\section{The new teacher in charge work stress questionnaire}

Hello! Thank you in spite of being very busy toglance involved in this questionnaire.

To understand the status of the new teacher in charge work pressure, to explore the sources of pressure, we designed the questionnaire below. To make the results more efficient, please you seriously honest orientation, information only for the use of statistics and research, your personal information will not be disclosed, individual rights not violated, please do not have any concerns. Thank you for your support and cooperation.

The following questions please on the following option to fit your situation "tick"

(1) You often pressure 

A. no pressure
B. a few pressure
C. small pressure generally pressure
D. much pressure
E. very great pressure

(2) The recent you often in daily work
A. the body tired
B. often angry with students
C. has no desire to do better
D. don't want to go into the teacher as an occupation
E. don't want to participate in any school activities
F. interaction with colleagues
G. felt hopeless about his career
H. to cope with strong psychological teaching work
I. other

(3) Poor classroom teaching language power of expression
A. no pressure
B. a few pressure
C. small pressure generally pressure
D. much pressure
E. very great pressure

(4) The school rules must complete the teaching work
A. no pressure
B. a few pressure
C. small pressure generally pressure
D. much pressure
E. very great pressure

(5) The lack of teaching materials, resources and equipment must be
A. no pressure
B. a few pressure
C. small pressure generally pressure
D. much pressure
E. very great pressure

(6) Class students learning ability difference is too big
A. no pressure
B. a few pressure
C. small pressure generally pressure
D. much pressure
E. very great pressure

(7) Class status
A. no pressure
B. a few pressure
C. small pressure generally pressure
D. much pressure
E. very great pressure

(8) Parents put the student's academic record low due to teachers' teaching ability is poor
A. no pressure
B. a few pressure
C. small pressure generally pressure
D. much pressure
E. very great pressure

(9) School teachers' ability not reasonable evaluation mechanism
A. no pressure
B. a few pressure
C. small pressure generally pressure
D. much pressure
E. very great pressure

(10) Have no confidence in teaching subjects
A. no pressure
B. a few pressure
C. small pressure generally pressure
D. much pressure
E. very great pressure

(11) The harmonious interpersonal relationship
A. no pressure
B. a few pressure
C. small pressure generally pressure
D. much pressure
E. very great pressure

(12) Social expectations of teachers and the request is too high
A. no pressure
B. a few pressure
C. small pressure generally pressure
D. much pressure
E. very great pressure

(13) He bear too many tasks, the responsibility is too big
A. no pressure
B. a few pressure
C. small pressure generally pressure
D. much pressure
E. very great pressure

(14) Frequent curriculum reform, teaching materials are not fixed
A. no pressure
B. a few pressure
C. small pressure generally pressure
D. much pressure
E. very great pressure

(15) The parents of students don't cooperate with her work
A. no pressure
B. a few pressure
C. small pressure generally pressure
D. much pressure
E. very great pressure

\section{Results of Questionnaire Investigation}

From respondents answered, I summarized the four aspects of the subject. About student 
management problems, and the problem of the relationship between the parents, and the problem of the relationship between the classroom teachers, school evaluation problem. After summarized four aspects, it respondents for these issues.

(1) Student management. Almost all of respondents have come from the pressure of students' management. As for a teacher in charge, the main work is to class's and grade's management. The stand or fall of a class is also on the teachers' management. The pressure is particularly big. Always want to be the head teacher of the new recognition, so, the effort on the management class must be recognized. New took over most of the students the temperament of the teacher is very don't understand, and each student has his own character. Some students interest in learning is not playing, don't concentrate in class, students abandon themselves. But for "exam-oriented education", don't allow students to abandon, so on to the students, the new head teacher requires special attention.

(2) Relationship with the parents. Now, almost most families are only children, so there will be the phenomenon of parents spoil, spoil the child. For the teacher in charge parents have asked, but never find their children. There are some children of single-parent families and parents don't even support the work of the school. Think with the teacher in charge, children do not need to his pipe. No matter, but requires the teacher to tube. Do not know how to do this creates the new teacher in charge's troubles. After that naturally tends to pressure.

(3) Relationship with the classroom teacher. The good relationship between colleagues is very important. Although classroom teachers just lesson, but also has conflict with the teacher in charge. Such as classroom teacher and class teacher to the student schedule conflicts, education concept of conflict, the teaching methods of conflict, etc. When there is no student in the classroom to listen well, following the teacher criticized the student habit is bad, not wise. It not only solves the problem, it will cause a lot of problems and the teacher in charge method is mainly deal with the problem. Improper handling can cause student's mood swings. So, with classroom teachers relationship is very important, otherwise it is another aspect of the pressure.

(4) Evaluation aspects of the school. School is teachers' existing environment. In the moment the only look at scores of times, for the assessment of the teacher in charge is very helpless, especially the new teacher in charge. Think when their first duty is how to make their own class to excel, but the only way is to rely on. But every student's thought is different, can't be a problem all will be in the first place, there is a problem of the actual situation of a class. Schools in order to achieve a particular effect always raise some unrealistic demands, so that the new teacher in charge pressure will be far more than the others. Old teacher have sometimes don't care, because they think they will not play what preheating, so they can lead to the development of the new teacher in charge up hard [4-5].

\section{Countermeasures}

Survey results show that the new teacher in charge's working pressure is there, and it is a lot of work pressure. Affect the new teacher in charge work pressure are mainly student management problems, problems on relationship with parents, colleagues, and school issues. When problems arise, we'll think of some way to go to solve the problem. The problems can't always exist. Solution is roughly as follows:

(1) Improve the system of school management, create the appropriate education environment. Education environment is a place where all students, teachers, good education environment to education, it is very necessary. First school management system is about to change, let everything become democratic, not the principal say what is what. Need everyone feel feasible to implement. In this way, it can reduce a lot of unreasonable high demand, so the teacher in charge also will have the enthusiasm to work. If everyone have the enthusiasm, so what's new teacher in charge there will be no burden, will work hard, quickly adapt to the environment, in this way, the pressure will also reduce a lot.

(2) The parent-school communication keep smooth, get enough external support. Parents are 
direct complained of a head teacher is good or bad person. The parents for the teacher in charge, is another. If the parents and the teacher in charge to cooperate well, the development of the students is very good, so all contradictions. However, if parents find their children than others, they don't think it is their child's question, will only feel is the teacher their own problems, then the problem will be more and more, the parents will be less and less. However, the teacher in charge and parents have very good communication, students have what problem, can do know each other, can according to find a solution for the problem, not to make unnecessary trouble. So, parent-school communication is very important.

(3) Strengthen the team cooperation consciousness, help each other between teachers. For a new teacher in charge, most of them are just out of the campus. So on the role transformation may need a period of time. During this time, if you have other people help, rather than the "damaged", so the effect is distinct. Between teachers and teachers is a team, we are family, have what difficulty will together, helping each other. The new teacher in charge needs to face a lot of a lot of problems, so, other teacher's help is also a kind of support, in this way you can also together to success. Good relationship with colleagues, in fact is very important.

(4) Need to self-development, but also the achievement of self. Nothing remains the same on yourself to embody and others is not the same as the "new", so as to make everyone agree with you, accept you. If everything is already outdated, why people have to follow you learning? So to improve themselves, improve their own, the students would be successful development. If has the same old ideas, students will be bored, long the bottom go to, everything is better than others, the pressure will follow, the last is to no avail. So, continuously development and achievement yourselves, let oneself better and students better [7-8].

\section{Conclusion}

The new teacher in charge's working pressure is everywhere and a note will make you in a lot of trouble. The new teacher in charge is not terrible, terrible is no way. This article through to the present situation of the new teacher in charge work pressure, find the right solution, make the new teacher in charge, at the same time that no longer have too much pressure.

\section{Acknowledgement}

This work is supported by Teaching reform project of Bohai university in 2015: Research on evaluation index system construction and action for process teaching of flipped classroom (BDJG-15-YB-B-012); Postgraduate teaching reform project of Bohai university in 2015: Action research on "ability to advanced" under the primary school education professional master talent training mode reform; Research project of undergraduate teaching reform of higher education in Liaoning Province in 2014: Action research on primary school education professional talent training mode reform based on standard.

\section{References}

[1] S. Y. Rao, "Influencing factors and inner mechanism of teachers' occupational stress," Education Research Monthly, vol. 27, no. 7, pp. 64-67, 2010.

[2] L. X. Yao, "Teacher stress management," Zhejiang University Press, pp. 38-40, 2005.

[3] Y. X. Liu, "Work stress and life: the management of individual coping and combination," China Social Sciences Publishing House, pp. 24-31, 2011.

[4] M. L. Hu, "The status quo and training strategies of primary school teacher in charge," Elementary school science (teacher forum), vol. 4, no. 8, pp. 119, 2012.

[5] Z. P. Huang, "Status analysis and countermeasures of head teacher work in China," Education Research Monthly, vol. 27, no. 3, pp. 85-87, 2010. 
[6] G. M. Wang, "Research on occupational stress and mental health status in the professional development of young teachers in primary schools," Master's degree of Liaoning Normal University, 2014.

[7] S. J. Guo, "A case study of primary school teachers' work pressure," Master's degree of Northeast Normal University, 2012. 